\title{
10. Trust, capabilities, confidence and basic income
}

\author{
Olli Kangas, Minna Ylikännö and Mikko \\ Niemelä
}

\section{INTRODUCTION}

Had John Lennon and Paul McCartney been sociologists, the title of their most famous and most referenced article might have been 'All You Need Is Trust'. Indeed, trust is something we need in everyday life. We could not interact with others in any positive or productive manner if we did not trust them; similarly, without trust, we could not properly interact with public institutions and authorities.

Mutual trust is a prerequisite for any sustainable social organization. Societies with low levels of generalised trust in fellow citizens and institutions inevitably struggle with political instability and corruption; hence, when reforming social institutions and experimenting with new social policy models, the emphasis should be placed on how to increase and maintain trust and, in a Putnamian sense, get people 'to bowl together' (Putnam, 2000).

The academic literature has typically separated trust into two distinct forms: trust in one's fellow citizens, also called generalised trust, and trust in institutions. Whether people trust institutions, or other people for that matter, has an effect on the functioning of society (Fukuyama, 1995, 2011; Stiglitz et al., 2018); thus, the importance of trust should not be ignored when assessing the functioning of existing national institutions or the pursuit of new policies.

According to the Cambridge Dictionary, 'trust' is the belief that the other person is good and honest and will not cause harm, or that something is safe and reliable, while 'confidence' refers to the quality of being certain of one's own abilities and plans for the future. For the purposes of our analysis, we define confidence as one's reliance on oneself and one's perceived ability to cope, meet future challenges, and be an influential actor in one's own life.

Even in the scientific literature, the concepts of trust and confidence are frequently used interchangeably. However, from a sociological perspective, it is useful to distinguish between the two. While they are interwoven and 
connected in many ways, they are not precisely the same (for a more detailed discussion, see for example Cofta, 2007). Both trust and confidence are related to the possibility of self-actualisation. The most prominent advocates of basic income, Guy Standing (2020) and Philippe Van Parijs (1995 and Van Parijs and Vanderborght, 2017), highlight the emancipatory value of basic income, which they view as greatly exceeding its monetary value. They also see basic income as an institutional device to enhance human agency and fortify individual self-governance and self-respect. These arguments have ideational resemblances to the works of Amartya Sen (1992, 1999, 2010) and Martha Nussbaum (2011), who emphasise the essential role of people's capabilities in creating well-being.

In this chapter, we ask how basic income, as an unconditional social transfer scheme, could be related to trust, capabilities and self-confidence. We start by discussing the concepts of trust, capability and confidence, presenting theory-based hypotheses and posing research questions on how basic income might be linked to generalised trust, trust in social institutions, (self-)confidence, and the set of capabilities needed to enable confidence building. After describing the outcome variables and methods used, we present the empirical analyses. The chapter ends with a general discussion of the results and their policy relevance.

\section{ALL YOU NEED IS TRUST}

Without trust, it would be difficult for people to interact with each other: life would be characterised by constant fear and full of vulnerabilities. Trust in fellow citizens can be seen as the glue that keeps societies together or the oil that lubricates human and economic transactions. Accordingly, a low level of trust in fellow citizens is correlated with low trust in the government, a low level of political efficacy, low confidence in one's own influence, lower voter participation, and less happiness and satisfaction in life (Putnam, 2000).

Perhaps the most well-known prophet of trust is Francis Fukuyama (1995, 2011, 2014), who emphasises, in several best-selling books, its crucial role in creating prosperous and economically sustainable societies. According to Fukuyama, a lack of mutual trust between fellow citizens and institutions has direct consequences for a nation's social order and economic trajectory. He further argues that 'a nation's well-being, as well as its ability to compete, is conditioned by a single pervasive cultural characteristic: the level of trust inherent in the society' (Fukuyama, 1995: 7).

Although trust makes life easier, vulnerability and uncertainty are always present in even the most trusting relationships (Heimer, 2001: 43). Historically, societies have developed different ways to reduce uncertainty and create trust, including various social institutions and social policy programmes. In par- 
ticular, universal social policy programmes are believed to enhance trust in society (for example, Rothstein, 2005; Svallfors, 2012; Larsen, 2016). Such universal social policies effectively represent the reciprocal nature of trust, that is, while being trusted, we are inclined to trust others (Ostrom, 1990). Social security systems that are built on the principle of trust - as, typically, all universal benefit schemes are - generate more trust than programmes based on continued screening and means-testing. In the former case, clients are treated equally, and, most importantly, they are trusted. In the latter case, clients are instead subject to extensive discretion and needs assessment, which at times can be arbitrary. While only predictable institutions can generate trust, the key question is how predictably welfare state institutions work (Sztompka, 1999; Tyler, 2001).

One of the crucial elements of universal social policies and their ability to generate trust is linked to the concept of recognition (Honneth, 1992; Honneth and Frazer, 2003) and the public acknowledgement of a person's status as a dignified member of society (see also Fukuyama, 2019). In the field of social policy, recognition means that the institution in question acknowledges clients as autonomous agents and takes their claims seriously. Accordingly, clients' perceptions of the treatment they receive from the authority will be generalised to other institutions, consequently either increasing or breaking trust in both social institutions and the public authorities implementing them. In Trust in the Law, Tyler and Huo (2002: 136) analyse the implications of procedural justice, stating,

...people do generalize from their personal experiences. People's perception of their treatment during an experience can have three types of broader impact: it shapes their trust in legal institutions and authorities; it shapes their trust in others in their community; and it shapes their identification with their community.

In the Nordic welfare states, universalism is a strong underlying principle during the implementation of social policies. The emphasis on the equality of citizens, instead of endless means-testing and screening, has created highly trusting societies. Indeed, comparisons between welfare regimes show that both generalised trust and trust in institutions are persistently higher in Nordic countries than in other welfare regimes. Further, trust is considered to be one of the key elements in the functioning of Nordic 'bumblebees', which, against all odds, have flown and continue to fly (for example, Andreasson, 2017; Halvorsen et al., 2016; Svendsen and Svendsen, 2016).

Against this theoretical and empirical background, we ask:

- How do the treatment group (receivers of the basic income) and the control group differ in their levels of trust in the social security system? 
- How do the treatment and control groups differ in their levels of trust in other societal institutions, including politicians, the legal system, and the police?

- How do the treatment and control groups differ in their levels of generalised trust?

\section{SELF-CONFIDENCE AND AGENCY IN ONE'S OWN LIFE}

A Google search on 'confidence' produces millions of hits, most of them manuals on how to build and boost self-confidence, including ' 3 Ways to be Confident', '10 Things You Can Do to Boost Self-confidence', 'Confidence-building Exercises', and 'Confidence Coaching', to name just a few. The apparent popularity of such manuals indicates that, in modern society, self-confidence is regarded as a valuable personal asset that helps people succeed in their lives.

However, the benefits of high levels of confidence go far beyond the mundane pecuniary benefits these cheapjack manuals promise. Bénabou and Tirole (2002) distinguish three intrinsic values of confidence. First, the consumption value describes how favourably we feel about ourselves: a positive self-image makes people happier, and happiness is, in turn, correlated with other good qualities of life (Layard, 2006). For example, multiple studies have shown its strong relationship with health (Atherton et al., 2016; Mann et al., 2004), although the direction of causality - if there is any - is difficult to prove.

Second, the signalling value states that by believing in ourselves, we signal to other people that we have valuable skills and abilities, which is helpful, for example, for securing employment. Third, the motivational value describes how self-confidence increases our willingness to be involved in new projects and increases our goal attainment aspirations, which, in Maslow's (1987) classical hierarchy of needs, represent self-actualisation (Bénabou and Tirole, 2002).

Based on these theories, we ask:

- How do the treatment and control groups differ in their levels of confidence in their future?

- How do they differ in their confidence in their own economic situation?

- How do they differ in their confidence in being able to cope with difficult life situations?

To actualise their aspirations, people need both confidence and sufficient capabilities upon which to base this confidence. Through John Rawls' ideas about 'primary goods' in Political Liberalism (1993) and Amartya Sen's 
(1992, 1999, 2010) emphasis on the role of people's capabilities, we move on to Martha Nussbaum (2011), who advances the idea of capability-building in human development. According to Nussbaum (2011: 193), there are two different forms of capabilities: an individual's own capabilities (internal capabilities) and those that are either fortified or hindered by social institutions and political systems (combined capabilities). Her central argument is that through combined capabilities, governments should advance measures that aim to strengthen people's internal capabilities.

In relation to the capability approach and basic income debate, we seek to answer the following:

- How do the treatment and control groups differ in their capabilities to undertake meaningful work?

- How do they differ in their capabilities to improve their material level of living?

- How do they differ in their perceptions of their capabilities to influence societal issues?

\section{DATA, VARIABLES AND ANALYSES}

Both generalised trust (trust in other people) and institutionalised trust (trust in the social security system, the legal system, and politicians) were measured on a scale from 0 to 10 , where the value 0 indicated total distrust and the value 10 indicated the highest possible level of generalised or institutionalised trust (see Table 10.1). The question on generalised trust was worded as follows: 'Please evaluate on a scale of 0 to 10 if most people can be trusted, or if you can't be too careful in dealing with people. Zero means you can't be too careful, and 10 means that most people can be trusted.'

Respectively, the wording of the question on institutional trust was as follows, with the institutions being the social security system, legal system, police, the EU, parliament, politicians, and political parties: 'Please evaluate on a scale of 0 to 10 how much you trust each of the following institutions. Zero means you do not trust an institution at all, and 10 means you have complete trust in it.'

The same measures were used in the European Social Survey (ESS, 2018), which allowed us to place our results for trust in a wider Finnish and European 
context (see Table 10.1). Questions on confidence and capabilities were posed as follows:

How do you feel the following things have developed in your life within the last two years?

Confidence in a) your own future, b) your own economic situation, and c) your ability to cope with difficult life situations;

Capability to a) have a meaningful job, b) improve your material level of living, and c) influence societal issues.

The time period of two years refers to the experimental period. The answer options for the above questions on confidence and capabilities were: (1) bad, (2) fairly bad, (3) neither bad nor good, (4) fairly good, (5) good, and (6) I do not know. In subsequent analyses, the last alternative was treated as a missing value (except in Table 10.2). Statistical significance (sig.) of differences in the average values (Table 10.1) and the relative shares (Table 10.2) between the treatment and control groups were based on the test of means (Table 10.1) and $\chi^{2}$-test (Table 10.2).

After presenting the cross-tabulated distributions of trust, confidence, and the respondents' perceptions of their capabilities, we merged the eight trust, three confidence, and three capacity variables into three additive and continuous variables. ${ }^{1}$ The trust variable ranged from 0 to a maximum value of 80 . The two other additive variables varied from the lowest value of 3 to the highest value of 15 . We then used these new variables in the summative structural equation models depicting the heuristic description of the multidimensional associations between the outcome variables (i.e. trust, confidence and capabilities) and several background variables.

Structural equation modelling (SEM) is a convenient heuristic tool for elaborating the descriptive associations between variables. Structural equation models allow us to theoretically model loops between variables and test whether there are associations; thus, we could make hypotheses, for example, on associations between respondents' levels of education and their health status, and then with their economic problems, allowing us to elaborate direct and indirect associations. We used SEM to produce path diagrams and evaluate the goodness of fit of the models. For the sake of simplicity, we only report the root mean square error of approximation (RMSEA), which is a commonly used indicator for goodness of fit that ranges from 0 to 1 . The smaller the value, the better the fit: while values less than 0.05 indicate a good fit, values greater than 0.10 indicate a poorly fitting model (Byrne, 2010: 80; Stata, 2011).

In the heuristic descriptions, we included all the variables gaining significance in the SEM models as explanatory variables, that is, age in six categories $(27-35 ; 36-40 ; 41-5 ; 46-50 ; 51-5$, and $56-61$ years of age $)$, gender $(1=$ female; $2=$ male $)$, education $(1=$ basic; $2=$ vocational; $3=$ high school; $4=$ 
college; 5 applied university; $6=$ university degree), subjective evaluation of own health status $(1=$ very bad; $2=$ bad; $3=$ fair $/$ cannot say; $4=$ good and $5=$ very good $)$, household size $(1=1$ person; $2=2$ persons. $\ldots 5=5$ or more persons), feeling of bureaucracy ('If you think about your life over the last two years, do you feel that there was too much bureaucracy involved in getting social benefits?'; $0=$ no; $1=$ do not know; $2=$ yes), and household economic situation (1 = Living comfortably on current income; $2=$ Coping on current income; 3 = Do not know; 4 = Difficult to live on current income; $5=$ Very difficult to live on current income). In the visual presentations, only statistically significant variables were included in the graphs.

\section{TRUST, CONFIDENCE AND CAPABILITIES}

The means of generalised trust and trust in institutions are shown in Table 10.1. The first observation is that Finland is a high-trust society: the level of trust with regard to all items was much higher among the Finnish European Social Survey (ESS) respondents than among those in the EU as a whole. The second observation is that the levels of trust are significantly lower among the unemployed than among the whole population; nevertheless, the observation that the Finnish unemployed are more trusting than average Europeans underlines the fact that Finland is a high-trust society.

However, when comparing either the unemployed or the experimental groups to the employed in Finland, Table 10.1 shows that the levels of trust in other people and institutions were lower in the former groups. Lower levels of trust among the unemployed may be because they, perhaps justifiably, blame the institutions for their misfortune, and, simultaneously, their misfortune may lead to a loss of generalised trust (Honneth, 1992; Hudson, 2006). When comparing the level of generalized trust and trust in institutions between the treatment and control groups of the basic income experiment, the treatment group displayed significantly higher levels of trust in all items, suggesting that after receiving basic income for two years, people are more likely to trust their fellow citizens and societal institutions, including the social security system.

Not all institutions are trusted equally, but some institutions are trusted more than others. Institutions enjoying high levels of trust are those for which there are no alternatives, such as the legal system, the police, and the social security system. Political institutions, which people can influence more or less directly, are less trusted. In our survey, these institutions included the EU, parliament, political parties and politicians. This pattern was the same in both our survey and the ESS (2018).

Next, we focused on the three aspects of confidence. As shown in Table 10.2, all the differences in opinions between the treatment and control groups were significant. We observed the highest confidence in coping with and 
managing difficult life situations: two-thirds of the treatment group and more than half of the control group claimed that in the last two years, they believed they had a good or fairly good likelihood of coping with difficult life events. The lowest confidence levels were observed in respondents' perceptions of managing their financial situations. While 44 percent of the treatment group considered their confidence in managing their financial situation was good or fairly good, the corresponding share in the control group was 33 percent.

Table 10.1 Institutional and generalised trust in the EU, in Finland and in the treatment and control groups (means)

\begin{tabular}{lccccccc}
\hline & \multicolumn{3}{c}{ European Social Survey 2018* } & \multicolumn{3}{c}{ Experiment } \\
& $\begin{array}{l}\text { EU (excl. } \\
\text { Finland) }\end{array}$ & $\begin{array}{c}\text { All } \\
\text { Finns }\end{array}$ & $\begin{array}{c}\text { Finns (excl. the } \\
\text { unemployed) }\end{array}$ & $\begin{array}{c}\text { Finnish } \\
\text { unemployed }\end{array}$ & $\begin{array}{c}\text { Treatment } \\
\text { group }\end{array}$ & $\begin{array}{c}\text { Control } \\
\text { group }\end{array}$ & sig. \\
\hline $\begin{array}{l}\text { Social } \\
\text { security }\end{array}$ & n.d. & n.d. & n.d. & n.d. & 6.65 & 6.36 & 0.024 \\
Legal & 5.18 & 7.17 & 7.20 & 6.19 & 6.73 & 6.46 & 0.044 \\
system & & & & & & & \\
Police & 6.28 & 8.12 & 8.15 & 7.44 & 7.86 & 7.71 & 0.231 \\
The EU & 4.43 & 5.40 & 5.42 & 4.76 & 4.86 & 4.55 & 0.038 \\
Parliament & 4.41 & 5.91 & 5.94 & 5.23 & 5.19 & 4.72 & 0.002 \\
Politicians & 3.54 & 4.90 & 4.93 & 4.19 & 4.45 & 3.81 & 0.006 \\
Political & 3.50 & 5.03 & 5.06 & 4.22 & 4.58 & 4.18 & 0.005 \\
parties & & & & & & & \\
Other & 4.91 & 6.94 & 6.96 & 6.33 & 6.66 & 6.32 & 0.007 \\
people & & & & & & & \\
\hline
\end{tabular}

Scale: $0=$ complete distrust and $10=$ complete trust, sig. $=$ significance of the differences in means between the treatment and control groups. *Authors' own calculations; the European Social Survey Round 9 (2018); n.d. = no data.

Respondents rated their capabilities - or in Nussbaum's (2011) term 'internal capability' - lowest in regard to the self-assessed possibility of having a say in societal issues. Only about 32 percent of the treatment group and 28 percent of the control group reported that they were confident they could influence societal issues over the last two years. 51 percent of the treatment group assessed their ability to perform meaningful work as good or fairly good, while this share was 43 percent in the control group. Respondents' perceptions of their capabilities to improve their material level of living were somewhat lower in both groups (41 percent and 30 percent, respectively). 
Table 10.2 Levels of confidence and perceptions of own capabilities in the treatment and control groups

\begin{tabular}{|c|c|c|c|c|c|c|c|c|}
\hline & Group & $\begin{array}{l}\mathrm{Bad} \\
(\%)\end{array}$ & $\begin{array}{l}\text { Fairly } \\
\text { bad } \\
(\%)\end{array}$ & $\begin{array}{l}\text { Neither } \\
\text { good nor } \\
\text { bad } \\
(\%)\end{array}$ & $\begin{array}{l}\text { Fairly } \\
\text { good } \\
(\%)\end{array}$ & $\begin{array}{l}\text { Good } \\
(\%)\end{array}$ & $\begin{array}{l}\text { Do not } \\
\text { know } \\
(\%)\end{array}$ & Sig. $\chi^{2}$ \\
\hline \multicolumn{9}{|l|}{ CONFIDENCE } \\
\hline \multirow[t]{2}{*}{ in own future } & Treatment & 6.6 & 7.3 & 24.4 & 36.6 & 25.6 & 1.5 & 0.000 \\
\hline & Control & 10.3 & 11.7 & 28.3 & 30.3 & 18.6 & 0.8 & \\
\hline \multirow{2}{*}{$\begin{array}{l}\text { in own } \\
\text { economic } \\
\text { situation }\end{array}$} & Treatment & 12.8 & 10.9 & 31.6 & 26.2 & 17.8 & 0.7 & 0.000 \\
\hline & Control & 19.6 & 15.3 & 31.2 & 20.4 & 12.1 & 1.4 & \\
\hline \multirow{2}{*}{$\begin{array}{l}\text { in coping with } \\
\text { difficult life } \\
\text { situations }\end{array}$} & Treatment & 6.0 & 4.4 & 21.5 & 35.0 & 30.8 & 2.2 & 0.003 \\
\hline & Control & 8.0 & 7.7 & 25.3 & 32.6 & 24.1 & 2.3 & \\
\hline \multicolumn{9}{|l|}{ CAPABILITY } \\
\hline \multirow{2}{*}{$\begin{array}{l}\text { to have } \\
\text { a meaningful } \\
\text { job }\end{array}$} & Treatment & 15.5 & 9.7 & 19.9 & 25.7 & 25.6 & 3.6 & 0.014 \\
\hline & Control & 19.8 & 12.8 & 20.2 & 22.7 & 20.5 & 4.4 & \\
\hline \multirow{2}{*}{$\begin{array}{l}\text { to improve } \\
\text { material level of } \\
\text { living }\end{array}$} & Treatment & 14.0 & 11.3 & 27.6 & 23.7 & 16.9 & 6.5 & 0.000 \\
\hline & Control & 20.7 & 16.3 & 28.9 & 18.7 & 11.1 & 4.2 & \\
\hline \multirow{2}{*}{$\begin{array}{l}\text { to influence } \\
\text { societal issues }\end{array}$} & Treatment & 14.8 & 17.6 & 29.4 & 17.9 & 14.5 & 5.8 & 0.000 \\
\hline & Control & 22.7 & 20.2 & 24.7 & 18.7 & 9.2 & 4.6 & \\
\hline
\end{tabular}

\section{BASIC INCOME, TRUST AND CONFIDENCE: A MULTIDIMENSIONAL RELATIONSHIP}

In this section, we provide tentative elaborations on how basic income might enhance people's trust and confidence. To do this, we created a structural equation model that visualised the multi-layered interactions between the 
outcome and background variables (Figure 10.1). The model fit was not perfect, although it was satisfactory (RMSEA $=0.078$ ).

As can be seen in Figure 10.1, there was no direct loop from treatment, that is, from receiving basic income to trust. However, indirect loops were revealed from treatment through economic problems and the experiences of bureaucracy to trust. The treatment group faced less bureaucracy when obtaining social benefits than the control group (see also Chapter 9), which is associated with lower levels of trust. Moreover, the treatment group reported fewer financial problems than the control group (see Chapter 8), which was positively related to the level of trust. ${ }^{2}$

Health affects people's ability to work and earn income (see Chapter 7), and, consequently, a strong and significant loop was seen in our model from subjective health to financial problems, which was, in turn, connected to trust. Furthermore, the smaller the household, the more severe financial problems it was likely to face. Educational attainment was positively connected to trust both directly and indirectly via health (higher education leads to better health) and economic problems (higher education leads to increased income).

One loop in our model ran from treatment to subjective health (significance $=0.010$ ). On the basis of our survey, we cannot state the causality of the relationship between these two variables, although it receives some support from Forget's $(2011,2018)$ analyses of the Mincome experiment implemented in the 1970s in Canada (see also Costello et al., 2003). In our future research, we plan to merge register data on medical diagnoses with the use of prescribed medicines to corroborate whether receiving basic income actually caused better health in the Finnish basic income experiment or whether this was an artefact produced by the survey.

As we did for trust, we also conducted SEM for confidence (RMSEA $=0.079$ ); visualisation not shown here). We were interested in both the relationship between treatment and confidence and the possible mediating role of capabilities when assessing the impact of treatment on confidence. Consequently, we used an additive variable measuring confidence as an outcome variable and an additive variable measuring respondents' capabilities as an independent background variable.

Figure 10.2 illustrates the loops from different background variables to confidence. The overall fit of the model was satisfactory (RMSEA $=0.073$ ). Parallel to the model for trust, treatment had no direct connection to confidence; however, we observed an indirect loop from treatment to confidence through capabilities. Accordingly, we also observed an indirect loop from experiences of bureaucracy to confidence through capabilities, signifying that basic income and, more generally, a less bureaucratic social security system, play a role in capability building, which then positively impacts confidence-building. 
Both direct and indirect loops were also seen through capabilities from financial problems, subjective health, and age to confidence, emphasising their importance in both capability- and confidence-building. Financial problems and age are negatively connected to capabilities; that is, more severe financial problems and a higher age predict lesser self-assessed capabilities; if one succeeds in capability-building, one should also gain more (self-)confidence.

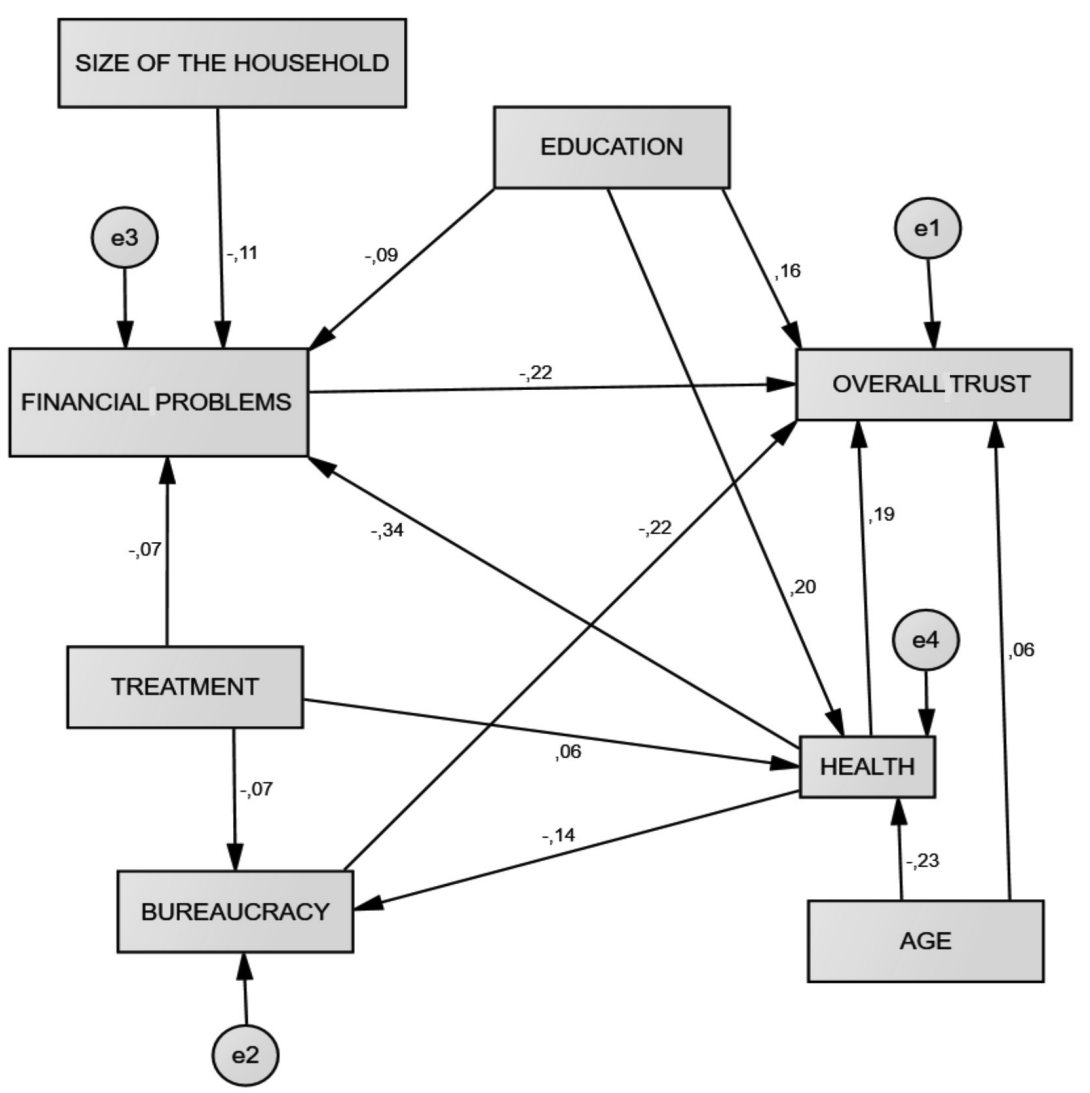

Figure 10.1 Heuristic model of associations between trust and receiving basic income and the background variables

Regarding the other variables, educational attainment had a direct association with confidence and an indirect association through financial problems and household size. Having a decent income is essential both for capability- and confidence-building; however, as our results show, the worse one's subjective 
health and the lower one's educational level, the more financial problems are likely and the more difficult it is to acquire and maintain capabilities and build confidence in oneself and one's future.

Outside of our main field of interest, we observed a direct negative loop from subjective health to experiences of bureaucracy, which indicates that either those with health issues confront the quite bureaucratic social administration more often than those with better health or that their rare acquaintances with the administration are more bureaucratic due to, for example, the more complex health issues to be solved when applying for social benefits. In sum, Figures 10.1 and 10.2 summarise the findings detailed in previous chapters and visualise the multi-dimensional connections between a set of background variables and trust, confidence and internal capabilities.

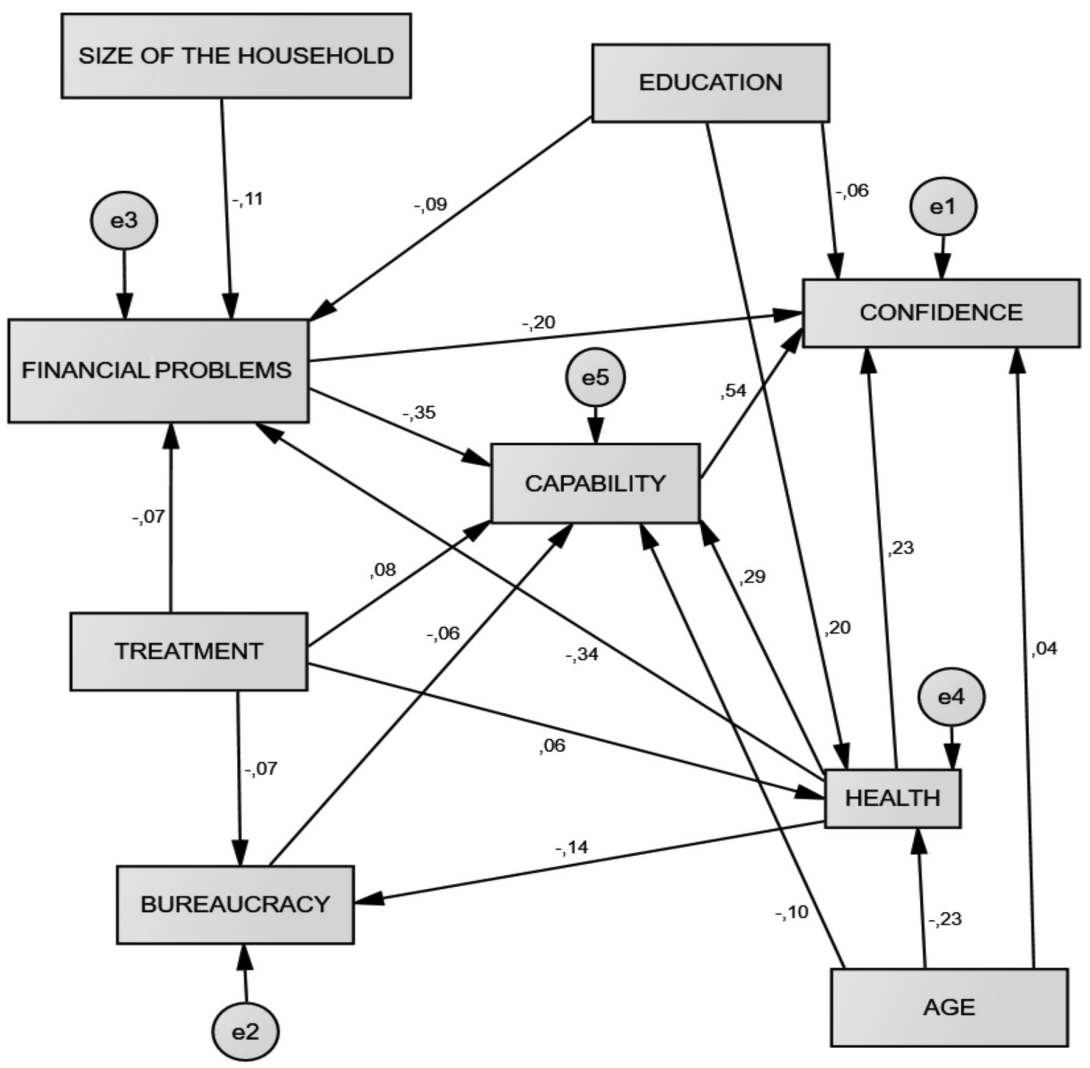

Figure 10.2 Heuristic model on associations between capability and receiving basic income and the background variables 


\section{CONCLUSIONS}

In this chapter, we were interested in the relationships between basic income, trust, confidence and internal capabilities. We asked whether the level of trust in other people and societal institutions, confidence in oneself and in one's future, and the assessed set of capabilities differed between those who received basic income in the Finnish basic income experiment and a control group.

The overall conclusion we can draw from the results of our analysis is that receiving basic income increases trust and confidence, although indirectly. To enhance people's trust and confidence, a decent income and good health are prerequisites: the more severe financial problems a household faces, and the more health problems a person has, the more difficult it is to enhance trust and confidence, even if social benefits are paid unconditionally.

A mundane and bold explanation for the observed higher levels of trust among basic income receivers might be that there is an unobserved heterogeneity between the survey respondents in the treatment and control groups. The analyses presented herein are based on a survey that, unfortunately, had low response rates; thus, the representativeness of the data can be legitimately questioned. However, if our tentative findings are corroborated either by previous empirical findings or by relevant theories, or preferably by both, then we can be more confident in our results, and it might be more interesting to tell a story that is grounded in the ample theoretical literature on trust and how it can evolve.

Both financial and health problems are common in the target group of the Finnish experiment, which comprised unemployed job seekers who received flat-rate unemployment benefits from the Social Insurance Institution of Finland (instead of earnings-related benefits from the country's unemployment funds) at the beginning of the experiment. These unemployed job seekers have typically been unemployed for a long period, for example, due to health problems (see also OECD, 2020). Indeed, as shown in Table 10.1, trust was lower among both the treatment and control groups than among non-unemployed fellow citizens. However, both trust and confidence were significantly higher in the treatment group than in the control group, indicating that basic income may enhance both, even if only indirectly.

In this chapter, we were also interested in the role of capabilities in confidence-building. Obviously, we cannot state any causal relationships between these two variables or other variables used in the SEM; however, as a heuristic tool, SEM helped us elaborate descriptive associations between variables. In the latter structural equation model (Figure 10.2), we observed an indirect loop from treatment to confidence through capabilities, asserting that receiving basic income positively correlates with capabilities and capabilities 
positively impact confidence. This result is unsurprising considering the vast literature on the central role of capabilities in well-being and life in general.

Theoretically, the higher levels of trust and self-confidence observed among the recipients of basic income may be explained by ideas of recognition and dignity, as posited by Honneth and Frazer (2003: 9), who argue ' ... that neither redistribution alone nor recognition alone can suffice to overcome injustice today; thus, they need somehow to be reconciled and combined'. Only recognition and redistribution together can allow for the right kind of justice, namely the ideal of 'participatory parity', which guarantees that each subject is afforded equal participation in public life, as demanded by Sen $(1999,2010)$ and Nussbaum (2011).

On the one hand, Frazer's ideas can be applied when trying to understand why a basic income might enhance trust and confidence. A recognition of clients' needs is an important aspect of decent treatment, although, on the other hand, recognition can also be used as an argument against basic income: a universal, homogeneous and unconditional benefit such as a basic income does not recognise individual or group-based differences in the same way that more targeted benefits do. However, targeted benefits generally include a lot of screening and discretion, which may cause feelings of unjust processes when social benefits are applied. If the system is not able to recognise the individual's needs and, at worst, bypasses them completely, the likelihood of breaking trusting relationships between the social security system and citizens is high.

To conclude, we need trust, but it is not all we need: trustworthy institutions are also required. Following Heimer's (2001) line of argumentation, we propose that those institutions that treat clients with dignity and decency and protect them from various vulnerabilities and risks in life enhance trust, strengthen self-confidence, and fortify capacity-building. A quotation from Standing (2020: 3) brings these ideas closer to the debate on basic income: 'A basic income would also strengthen social solidarity, including human relations: it would be an expression that we all are part of a national community, sharing the benefits of the national public wealth created over our collective history'.

The main lesson from the Finnish basic income experiment could be understood as follows. Decent minimum income protection - be it basic income or the Finnish variant of residence-based basic security - is a necessary condition for the fulfilment of the grand goals the protagonists of the basic income advocate. However, this is not a sufficient condition for achieving these goals. In addition, we also need the amplitude of social, health care, educational, and employment services in order to support individuals to fully utilise their internal capabilities.

Finally, considering the empirical results from our own survey and the vast academic literature on trust, confidence, and capabilities, we can confidently 
argue that the questions of the relationships between basic income and trust, basic income and confidence, and basic income and capabilities are of the utmost relevance, and that enhancing trust and confidence, strengthening citizens' capabilities and ensuring decent social security should be the most important goals when reforming the current social security systems in Finland and elsewhere.

\section{NOTES}

1. Cronbach's alpha for the eight trust variables was 0.919 , for the three confidence variables 0.821 , and for the three variables measuring capabilities 0.709 .

2. This result was also corroborated by analyses performed on the ESS 2018 data.

\section{REFERENCES}

Andreasson, U. (2017), Trust - The Nordic Gold, Nordic Council of Ministers Analysis Report. Copenhagen: Nordic Council of Ministers.

Atherton, S., Antley, A., Evans, N., Cernis, E., Lister, R., Dunn, G., Slater, M. and Freeman, D. (2016), 'Self-Confidence and Paranoia: An Experimental Study Using an Immersive Virtual Reality Social Situation', Behavioural \& Cognitive Psychotherapy, 44(1), 56-64.

Bénabou, R. and Tirole, J. (2002), 'Self-Confidence and Personal Motivation', The Quarterly Journal of Economics, 117(3), 871-915.

Byrne, B. (2010), Structural Equation Modelling with AMOS, London: Routledge.

Cofta, P. (2007), Trust, Complexity and Control: Confidence in a Convergent World, Chichester: John Wiley \& Sons.

Costello, E. J., Compton, S. N., Keeler, G. and Angold, A. (2003), 'Relationships between Poverty and Psychopathology: A Natural Experiment', JAMA, 290(15), 2023-9.

ESS (2018), Round, E. 9, European Social Survey Round 9 Data, Data File edition 3.0, Norway: NSD - Norwegian Centre for Research Data, Data Archive and Distributor of ESS Data for ESS ERIC, available at doi:10.21338/NSD-ESS9-2018 (accessed 11 December 2020).

Forget, E. L. (2011), 'The Town with No Poverty: The Health Effects of a Canadian Guaranteed Annual Income Field Experiment', Canadian Public Policy, 37(3), 283-305.

Forget, E. (2018), Basic Income for Canadians. The Key to a Healthier, Happier, More Secure Life for All, Toronto: James Lorimer and Co.

Fukuyama, F. (1995), Trust. The Social Virtues and the Creation of Prosperity, London: Pelican Books.

Fukuyama, F. (2011), The Origins of Political Order. From Prehuman Times to French Revolution, London: Profile Books.

Fukuyama, F. (2014), Political Order and Political Decay. From the Industrial Revolution to the Globalisation of Democracy, London: Profile Books.

Fukuyama, F. (2019), Identity: Contemporary Identity Politics and the Struggle for Recognition, London: Profile Books. 
Halvorsen, R., Hvinden, B. and Schoyen, M. A. (2016), 'The Nordic Welfare Model in the Twenty-First Century: The Bumble-Bee Still Flies!', Social Policy \& Society, 15(1), 57-73.

Heimer, C. (2001), 'Solving the Problem of Trust', in Cook, K. S. (ed.), Trust in Society, New York: Russell Sage Foundation, pp. 40-88.

Honneth, A. (1992), The Struggle for Recognition: The Moral Grammar of Social Conflicts, Cambridge: Polity Press.

Honneth, A. and Frazer N. (2003), Redistribution or Recognition?: A Political-Philosophical Exchange, London: Verso.

Hudson, J. (2006), 'Institutional Trust and Subjective Well-Being across the EU', Kyklos, 59(1), 43-62.

Larsen, C. A. (2016), The Institutional Logic of Welfare Attitudes: How Welfare Regimes Influence Public Support, London: Routledge.

Layard, R. (2006), Happiness. Lessons from a New Science, London: Penguin Books.

Mann, M., Hosman, C., Schaalma, H. and de Vrieset, N. (2004), 'Self-Esteem in a Broad-Spectrum Approach for Mental Health Promotion', Health and Education Research, Health Education Research, 19(4), 357-72.

Maslow, A. H. (1987), Motivation and Personality, Delhi: Pearson Education.

Nussbaum, M. C. (2011), Creating Capabilities: The Human Development Approach, Cambridge, London: The Belknap Press of Harvard University Press.

OECD (2020), Faces of Joblessness. A People-centred Perspective on Employment Barriers and Policies, Paris: OECD.

Ostrom, E. (1990), Governing the Commons: The Evolution of Institutions for Collective Action, Cambridge: Cambridge University Press.

Putnam, R. (2000), Bowling Alone: The Collapse and Revival of American Community, New York: Simon \& Schuster.

Rawls, J. (1993), Political Liberalism, New York: Columbia University Press.

Rothstein, B. (2005), Social Traps and the Problem of Trust, Cambridge: Cambridge University Press.

Sen, A. (1992), Inequality Re-Examined, New York and Oxford: Clarendon Press, Oxford University Press.

Sen, A. (1999), Development as Freedom, New York: Oxford University Press.

Sen, A. (2010), The Idea of Justice, London: Penguin Books.

Stata (2011), Structural Equation Modelling, Release 12, TX: College Station: A Stata Press Corporation.

Stiglitz, J., Fitoussi, J. and Durand, M. (eds) (2018), For Good Measure: Advancing Research on Well-Being Metrics Beyond GDP, Paris: OECD.

Standing, G. (2020), Battling Eight Giants: Basic Income Now, London: Tauris.

Svallfors, S. (2012), 'Welfare States and Welfare Attitudes', in Svallfors S. (ed.), Contested Welfare States. Welfare Attitudes in Europe and Beyond, Stanford: Stanford University Press, pp. 1-24.

Svendsen, G. and Svendsen, G. (2016), Trust, Social Capital and the Scandinavian Welfare State, Cheltenham: Edward Elgar Publishing.

Sztompka, P. (1999), Trust. A Sociological Theory, Cambridge: Cambridge University Press.

Tyler, T. (2001), 'Why Do People Rely on Others? Social Identity and the Social Aspect of Trust', in Cook K. S. (ed.), Trust in Society, New York: Russell Sage Foundation, pp. 285-306.

Tyler, T. R. and Huo, Y. J. (2002), Trust in the Law: Encouraging Public Cooperation with the Police and Courts, New York: Russell Sage Foundation. 
Van Parijs, P. (1995), Real Freedom for All: What (If Anything) Can Justify Capitalism, Oxford: Oxford University Press.

Van Parijs, P. and Vanderborght, Y. (2017), Basic Income: A Radical Proposal for a Free Society and a Sane Economy, Cambridge: Harvard University Press. 